\title{
Weight in Community College Students: A Move to Intervention Design
}

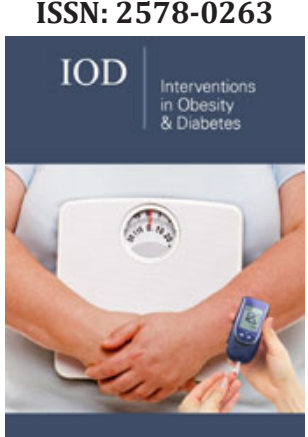

*Corresponding author: Janna Stephens, College of Nursing, Ohio State University, USA

Submission: March 30,2019

Published: 捡April 29,2019

Volume 2 - Issue 5

How to cite this article: Janna S, Hailey M. Weight in Community College Students: A Move to Intervention Design. Interventions Obes Diabetes. 2(5). IOD.000549.2019. DOI: 10.31031/IOD.2019.02.000549

Copyright@ Janna Stephens, This article is distributed under the terms of the Creative Commons Attribution 4.0 International License, which permits unrestricted use and redistribution provided that the original author and source are credited.

\author{
Janna Stephens ${ }^{1 *}$ and Hailey Miller ${ }^{2}$ \\ ${ }^{1}$ College of Nursing, USA \\ ${ }^{2}$ School of Nursing, USA
}

\begin{abstract}
Young adults in college are at high risk for being overweight or obese. Community college students make up about $40 \%$ of all undergraduate students in the United States, yet they are grossly underrepresented in research focused on college students. This review will explore the lifestyle habits and other factors related to weight gain in the community college student with a goal to drive intervention design.
\end{abstract}

Keywords: Community college; Weight loss; Intervention design

Abbreviations: BMI: Body Mass Index; US: United States

\section{Introduction}

An increased body mass index (BMI) is associated with several chronic conditions, including hypertension, type 2 diabetes, and heart disease [1,2]. An increased BMI is the most prevalent public health concern in the United States, impacting over two-thirds of US adults. One young adult is at a high risk for overweight and obesity as they transition from adolescence into adulthood. Several factors are believed to be associated with increasing risk for being overweight and obese. These factors include poor diet, lack of physical activity, and stress [3].

More than 6 million students attend community colleges, totaling about $36-40 \%$ of all undergraduate students in the country [4]. The demographics of community colleges are very diverse, with $25 \%$ of students identifying as Hispanic and $13 \%$ identifying as Black [5]. Fifty-four percent of students attending community colleges are under the age of 22 and only $9 \%$ are above the age of forty [5]. In addition, $29 \%$ are first-generation college students and $15 \%$ are single parents [5]. Literature has shown that two-year community college students engage in less healthy behaviors, including poorer dietary choices and less physical activity compared to four-year college students.

Additionally, female community college students were more likely to be overweight and obese [6]. Students report other conditions associated with cardiovascular disease as well; about $1.2 \%$ report having diabetes and $3 \%$ report having high blood pressure [3]. Two-year community colleges also have an increased enrollment of Hispanic and African American students compared to four-year universities, both of which experience higher rates of overweight and obesity [2,7]. However, the community college population is understudied. According the American College Health Association, only 9\% of schools surveyed for the National College Health Assessment were community colleges [3]. In a recent review of the literature focused on community college students and health, it was indicated that there were only 10 studies focused on diet and six studies focused on physical activity behaviors in the past 25 years in this population [8]. This review is focused on examining factors related to weight gain and weight loss in community college students to design tailored interventions for weight loss.

\section{Discussion}

\section{Health behaviors related to weight}

A comprehensive examination of health behaviors in community college students led to results indicating poor eating habits and poor exercise habits. In a study conducted in diverse 
inner-city community college students, $60 \%$ reported not meeting physical activity guidelines and only $1.5 \%$ had the recommended fruit and vegetable servings per day [9]. In another study, more than $50 \%$ of community college students reported buying fast food at least 1-2 times per week and consumed, on average, 22 sugary or sugar-free drinks per month. In addition, levels of physical activity were below the recommendation and students reported 5 or more hours per day of sedentary time [10]. An additional study examined fruit intake in female community college students and $33 \%$ indicated eating less than two servings per day [11]. When examining factors that are related to BMI, Pelletier et al. reported that high stress levels are associated with a higher prevalence of overweight/obesity and financial strain was significantly associated with overweight/obesity [12]. Obesity has been shown in community college students to negatively impact a student's education. One study reported that community college students who were overweight or obese receive significantly lower grades but show no differences in intelligence or achievement test scores [13]. Another study in two-year colleges reported that students who feel that they have poor physical health and have a poor sense of well-being are more likely to consider dropping out of college [14].

Focus group trials have been conducted in community college students. To date, we located two trials that included qualitative methods designed to understand weight perceptions and weight loss/maintenance interventions. In one study, students expressed a lack of time, stress, and lack of sleep leading to unhealthy eating habits and a lack of focus on health [15]. Students also expressed that the college environment could be a place for intervention delivery and that the school could do more for student health. Students also want a comprehensive program and to choose their mode of delivery [15]. Another focus group trial conducted in 2018 confirmed the results that students desire a comprehensive program for weight, including nutrition, physical activity, and other lifestyle habits [16]. Students also stressed having too many responsibilities and therefore a lack of time. Students suggested for interventions to include health coaches who have been overweight or obese previously and also to tailor the program to their specific needs [16].

\section{Current intervention studies}

There have been very few intervention studies focused specially on the community college population. One study, called the Choosing Health Options in College Environments and Settings was a randomized controlled trial focused on the prevention of weight gain for students entering two-year colleges [17]. Using a college course on health weight behaviors and a social networking and support website researchers examined changes in BMI and weight at 24 months. Although there were no significant differences in BMI at 24 months, those in the intervention who were overweight or obese at baseline were more likely to be at a normal weight post trial [17]. This is currently the only intervention study the authors found solely focused on the community college population and weight.

\section{Conclusion}

Community college students make up a large proportion of the undergraduate student population, however, are dramatically understudied in terms of health outcomes, specifically overweight and obesity. Given their unique circumstances and reportedly poor health, the community college population is a crucial setting to promote health behavior and implement health interventions focusing on weight control and weight gain prevention. A program designed to help minimize weight gain or promote weight loss should be tailored and specific to those participating. In addition, researchers should strive to personalize the delivery of content and should make programs comprehensive and not solely focused on diet and physical activity.

\section{Acknowledgment}

HM is supported by a predoctoral fellowship in Interdisciplinary Training in Cardiovascular Health Research (T32NR012704).

\section{References}

1. Ogden C, Carroll M, Kit B, Flegal K (2014) Prevalence of childhood and adult obesity in the united states, 2011-2012. JAMA 311(8): 806-814.

2. Fryar C, Carrol M, Ogden C (2018) Prevalence of overweight, obesity and severe obesity among adults 20 and over: United states, 1960-1962 through 2015-2016. NCHS Health E-Stats, pp. 1-6.

3. ACHA- NCHS II (2013) Undergraduate student reference group executive summary 2015.

4. https://nces.ed.gov/programs/coe/indicator_cha.asp

5. https://www.aacc.nche.edu/research-trends/fast-facts/

6. Laska M, Pasch K, Lust K, Story M, Eglinger E (2011) The differential prevalence of obesity and related behaviors in two-vs. four-year colleges. Obesity (Silver Spring) 19(2): 453-456.

7. Ma J, Baum S (2016) Trends in community colleges: Enrollment, pirces, completion and student debt and Completion.

8. Pokhrel P, Little M, Herzog T (2014) Current methods in health behavior research among U.S. community college students: A review of the literature. Eval Health Prof 37(2): 178-202.

9. Heller J, Sarmiento A (2016) Health behaviors of culturally diverse inner-city community college students. J Am Coll Health 64(8): 651-663.

10. Nanney M, Lytle L, Farbakhsh K, Moe SG, Linde JA, et al. (2015) Weight and weight-related behaviors among 2-year college students. J Am Coll Health 64(3): 221-229.

11. Shive S, Neyman M (2003) Prevalence and predictors of fruit intake among community college women in the extended opportunity program and services. Californian Journal of Health Promotion 1(1): 91-102.

12. Pelletier J, Lytle L, Laska M (2016) Stress, health risk behaviors and weight status among community college students. Health Educ Behav 43(2): 139-144.

13. MacCann C, Roberts R (2013) Just as smart but not as successful: Obese students obtain lower school grades but equivalent test scores to nonobese students. Int J Obes (Lond) 37(1): 40-46.

14. Hixenbaugh P, Dewart H, Towell T (2012) What enables students to succeed? an investigation of socio-demographic, health and student experience variables. Psychodynamic Practice 18(3): 285-301.

15. Linde J, Sevcik S, Petrich C, Gardner JK, Laska MN, et al. (2014) Translating a health behavior change intervention for delivery to 2-year college students: The importance of formative research. Transl Behav Med 4(2): 160-169. 
16. Stephens J, Perkins A (2019) Black community college students and opinions and beliefs on weight in the community: A focus group study. Health 11(1): 57-66.
17. Lytle L, Laska M, Linde J, Moe SG, Nanney MS, et al. (2017) Weight-gain reduction among 2-year college students: The CHOICES RCT. Am J Prev Med 52(2): 183-191.

For possible submissions Click below: 